\title{
Development of an LC-MS method for determination of nitrogen-containing heterocycles using mixed-mode liquid chromatography
}

\author{
Mohammad Sajjad Abdighahroudi ${ }^{1,2}$ (D) Holger V. Lutze ${ }^{1,2,3,4}$ (D) Torsten C. Schmidt ${ }^{1,3,4}$ (D)
}

Received: 10 January 2020 / Revised: 16 March 2020 / Accepted: 16 April 2020 / Published online: 26 May 2020

(C) The Author(s) 2020

\begin{abstract}
$\mathrm{N}$-containing heterocycles (NCHs) are largely used as precursors for pharmaceuticals and can enter the environment. Some $\mathrm{NCHs}$ have been shown to be toxic, persistent, and very mobile in the environment. Thus, they have received increasing attention in the past years. However, the analysis of these polar compounds in environmental samples is still a challenge for liquid chromatography. This paper investigates the use of mixed-mode liquid chromatography (MMLC), which has reversed-phase and ion exchange characteristics for measurements of $\mathrm{NCHs}$ in water. $\mathrm{NCHs}$ with low $\mathrm{p} K_{\mathrm{a}}(\mathrm{i} . \mathrm{e} .,<2.5)$ display mainly reversedphase interactions (neutral species) with the stationary phase and those with higher $\mathrm{p} K_{\mathrm{a}}$ (i.e., $>5$ ) interact by a mixture of reversed-phase/ion exchange/HILIC mechanism. It was also shown that the presented method performs well in the quantification of the majority of the selected NCHs in surface water with MDLs between 3 and $6 \mu \mathrm{g} / \mathrm{L}$, a low matrix effect and recoveries in the range of $77-96 \%$ except for pyridazine exhibiting $32 \%$ were achieved. The method was successfully employed to follow the degradation of NCHs in ozonation.
\end{abstract}

Keywords Nitrogen-containing heterocycles $\cdot$ Liquid chromatography $\cdot$ Reversed-phase $\cdot$ Cation exchange $\cdot$ Mixed-mode chromatography

Published in the topical collection Persistent and Mobile Organic Compounds - An Environmental Challenge with guest editors Torsten C. Schmidt, Thomas P. Knepper, and Thorsten Reemtsma.

Electronic supplementary material The online version of this article (https://doi.org/10.1007/s00216-020-02665-x) contains supplementary material, which is available to authorized users.

Holger V. Lutze

H.Lutze@iwar.tu-darmstadt.de

Torsten C. Schmidt

torsten.schmidt@uni-due.de

1 Faculty of Chemistry, Instrumental Analytical Chemistry, University of Duisburg-Essen, Universitätsstraße 5, 45141 Essen, Germany

2 IWAR, Technical University Darmstadt, Franziska-Braun Str. 7, 64287 Darmstadt, Germany

3 IWW Water Centre, Moritzstraße 26, 45476 Mülheim an der Ruhr, Germany

4 Centre for Water and Environmental Research (ZWU), Universitätsstraße 5, 45141 Essen, Germany

\section{Introduction}

$\mathrm{N}$-containing heterocycles $(\mathrm{NCH})$ are a group of compounds with wide occurrence in the environment and broad application in chemistry [1-3]. They have been detected at industrial and agricultural sites $[4,5]$, groundwater [6-10], and surface water $[11,12]$. They were also found in coal liquids, shale oil, surface waters such as lakes, and marine sediments [13]. The features of chemicals such as pharmaceuticals, industrial solvents, ionic liquids, and pesticides are based on $\mathrm{NCH}$ moieties [14-16]. Important moieties of, e.g., pharmaceuticals, are piperidine, pyridine, and imidazole [17]. Aromatic $N$-heterocycles such as pyrazole, pyridine, and pyrazine are also byproducts of chemical processes such as acrylonitrile manufacturing [18].

Many NCHs are mutagenic, carcinogenic, and thus, hazards to the environment and human health [19], e.g., pyridine is toxic for several bacterial species and a strong odor compound [20]. It can cause weakness, lung and liver damage, and gastrointestinal inflammation in humans by acute exposure [15]. NCHs such as pyridine and imidazole are categorized 
as water hazard category 2 (significantly hazardous to the aquatic environment), and pyrazole is categorized as water hazard category 3 (highly hazardous to the aquatic environment) by German Environment Agency (Umweltbundesamt UBA) (Table 1) [22]. Hence, UBA has set a provisionary water standard of $3 \mu \mathrm{g} / \mathrm{L}$ for pyrazole [24].

Due to their basic properties (Table 1), NCHs are readily water soluble as cations at typical $\mathrm{pH}$ values of surface and groundwaters and thus mobile in the aquatic environment. $\mathrm{NCHs}$ are not directly photo-oxidized due to low absorption maxima [8], and some of them, such as pyrazole, are poorly biodegradable [25]).

To abate NCHs, different methods can be utilized [12, 15, 19]. Ozonation is one of the methods that is extensively used to eliminate NCHs, whether in wastewater [12] or process studies [26, 27]. Monitoring these methods and processes requires specific and sensitive measurement of NCHs.

The high affinity of NCHs towards the aqueous medium results in a challenge for classical reversed-phase liquid chromatography (RPLC) separation techniques [28]. For polar and small compounds such as imidazole, piperidine, and pyridine, there is hardly any retention on C18 columns [14, 29, 30]. This causes co-elution with non-retarded matrix components present in the sample, such as salts, and thus interferences in the detection of these NCHs (e.g., spectral interference (UVvis detection) or ionization (MS-detection)) [31]. Moreover, solid-phase extraction (SPE) hardly enriches polar compounds such as NCHs [32-34]. Using ion chromatography (IC) [35] or ion pair chromatography [36] retention of $\mathrm{NCHs}$ was accomplished. However, the use of nonvolatile buffers, necessity for strong ion-pairing agents, and high water percentage render hyphenation with MS challenging, which is the detection method of choice.

Recently the use of mixed-mode liquid chromatography (MMLC) was suggested for the separation of polar and charged compounds as an alternative to hydrophilic interaction liquid chromatography (HILIC) [14, 37]. MMLC provides different modes of interactions with the analytes, such as hydrophobic interaction and ion exchange [38]. This can be used for separation of analytes with very different properties. For example, MMLC columns with anion or cation exchangers embedded in their hydrophobic alkyl chains [37] were used for the simultaneous measurement of cationic, zwitterionic, and neutral compounds previously [39]. Moreover, obstacles such as long equilibration time and use of organic solvent in the sample do not exist in MMLC compared to HILIC [33, 34]. However, up to now, MMLC was not used for the determination of NCHs.

The present work aims to develop an MMLC-MS method for the analysis of NCHs in water samples. It furthermore characterizes the separation mechanisms and employs the method in measurement of selected $\mathrm{NCHs}$ in the river water matrix. Applicability of the method in process monitoring will be tested for ozonation of the same water matrix.

Table 1 Physical and chemical properties of selected N-heterocycles

\begin{tabular}{|c|c|c|c|c|c|c|c|}
\hline Compound & $\mathrm{Mw}$ & {$[\mathrm{M}+\mathrm{H}]^{+}(\mathrm{m} / \mathrm{z})$} & Structure & $\mathrm{p} K_{\mathrm{a}}^{\mathrm{a}}[21]$ & $\log \mathrm{P}[21]$ & $\log (D)^{b}$ & Water hazard category $[22$ \\
\hline Imidazole & 68.07 & 69.07 & & 6.99 & -0.08 & -0.38 & 2 \\
\hline Pyrazole & 68.07 & 69.07 & & 2.49 & 0.33 & 0.33 & 3 \\
\hline Pyridine & 79.10 & 80.10 & & 5.23 & 0.65 & 0.64 & 2 \\
\hline Pyridazine & 80.09 & 81.09 & & 2.24 & -0.72 & -0.72 & Not Available \\
\hline Piperidine & 85.15 & 86.15 & & 11.123 & 0.85 & -3.27 & 1 \\
\hline
\end{tabular}

${ }^{\text {a }}$ Conjugated acid

${ }^{\mathrm{b}}$ At pH 7 calculated based on [23] 


\section{Material and methods}

\section{Chemicals}

All chemicals were commercially available and used as received (purity is presented in parenthesis): piperidine (ReagentPlus®, 99\%) Sigma-Aldrich, pyridine (anhydrous, 99.8\%) Sigma-Aldrich, imidazole (ACS reagent, $\geq 99 \%$ ) Sigma-Aldrich, pyrazole (98\%) Sigma-Aldrich, pyridazine $(98+\%)$ Alfa Aesar. Water for chromatography (LC-MS Grade) LiChrosolv Merck Millipore, acetonitrile (ACN) HiPerSolv CHROMANORM® for LC-MS ( $\geq 99.9 \%$,) VWR Chemicals, formic acid Suprapur (98-100\%) Merck Millipore, nitrogen gas (>99\%) and oxygen gas $(99.998 \%)$ from Air Liquid, Oberhausen.

\section{Instrumentation}

The following instruments were used: $\mathrm{pH}$ meter from Metrohm $827 \mathrm{pH}$, TOC analyzer from Shimadzu TOC-L with ASI-L autosampler, and TOC Control-L Software. HPLC from Agilent Technologies (1100 Series) with Autosampler coupled with a Quadrupole LC/MS 6120 Mass spectrometer. LC-MS online software was used for data acquisition and processing. ESI was operated as follows: API-ES-positive mode, drying gas (nitrogen) temperature $250{ }^{\circ} \mathrm{C}$, drying gas flow rate $11.0 \mathrm{~L} / \mathrm{min}$, nebulizer pressure $35 \mathrm{psi}$, capillary voltage $3.2 \mathrm{kV}$. The temperature of the column oven was kept constant at $30{ }^{\circ} \mathrm{C}$ in all measurements, and the flow rate was $300 \mu \mathrm{L} /$ min with $5 \mu \mathrm{L}$ injection volume. A Primesep 200 column $(2.1 \times 150 \mathrm{~mm} 5$ - $\mu \mathrm{m}$ particle size and $100-\mathrm{A}$ pore size $)$ and guard column $(2.1 \times 5 \mathrm{~mm})$ from SIELC technology were used for separation. Single ion monitoring was used to measure real water samples. For further details on MS parameters, see Electronic Supplementary Material (ESM) Table S4.

Ozone was generated by continuous purging of ozone enriched $\mathrm{O}_{2}$ stream into ultrapure water, using a Philaqua 802 x ozone generator from BMT Messtechnik Berlin. The concentration of ozone was determined by the determination of UV-absorption ( $\varepsilon_{\text {ozone }}$ at $258 \mathrm{~nm}=2950 \mathrm{M}^{-1} \mathrm{~cm}^{-1}$ [40]) using a Shimadzu UV-1800 spectrometer. The used absorption coefficient is different from the more recently published one of $3200 \mathrm{M}^{-1} \mathrm{~cm}^{-1}$ [41]; however, it includes losses of ozone happening during the transfer of the ozone stock solution to the UV-vis spectrometer.

\section{Chromatography}

For optimization of the separation using MMLC, one has to determine the main separation modes. Based on reversedphase (RP) interaction, an increase of the organic phase volume fraction (here ACN), and thus a decrease of aqueous volume fraction, results in a decrease of the retention factor
(Eq. 1) [42].

$\log \mathrm{k}^{\prime}=-\mathrm{S} \times \delta_{\mathrm{ACN}}+\log \mathrm{k}_{\mathrm{A}}^{\prime}$

where $\mathrm{k}^{\prime}$ is the observed retention factor, $\delta_{\mathrm{ACN}}$ is the volume fraction of ACN, $S$ is the slope the linear line, $\mathrm{k}_{\mathrm{A}}^{\prime}$ is the retention factor when the volume fraction of $\mathrm{ACN}$ is zero, while for ion exchange (IE) chromatography, the retention factor is based on Eq. 2 [42].

$\log \mathrm{k}^{\prime}=-\mathrm{Z} \times \log C_{s}+\log \mathrm{k}_{z}^{\prime}$

where $C_{\mathrm{s}}$ is the concentration of counter ion (hydrogen ion), $Z$ is the slope of the linear line, and $\mathrm{k}_{\mathrm{z}}^{\prime}$ is a constant related to ion exchange properties of eluent and stationary phase [43].

To investigate the role of both IE and RP interactions for retention of different NCHs, a $1000 \mu \mathrm{g} / \mathrm{L}$ sample was analyzed using isocratic conditions with different $\delta_{\mathrm{ACN}}$. In these experiments, the water was acidified with formic acid (FA), but ACN was not acidified. By mixing not acidified ACN with acidified water up to $60 \%$, the final $\mathrm{pH}$ of the eluent will increase linearly according to Eq. 3 [44].

${ }_{\mathrm{w}}^{\mathrm{s}} \mathrm{pH}={ }_{\mathrm{w}}^{\mathrm{w}} \mathrm{pH}+m_{\mathrm{pH}} \times \delta_{\mathrm{ACN}}$

where ${ }_{\mathrm{w}}^{\mathrm{s}} \mathrm{pH}$ is the $\mathrm{pH}$ of the mixture, ${ }_{\mathrm{w}}^{\mathrm{w}} \mathrm{pH}$ is the initial $\mathrm{pH}$ of the water before mixing with $\mathrm{ACN}$, and $m_{\mathrm{pH}}$ is the proportionality coefficient for the $\mathrm{pH}$ variation. $m_{\mathrm{pH}}$ also depends on the concentration of acid and initial $\mathrm{pH}$, which is discussed by Subirats et al. [44]. As a result of increasing $\mathrm{pH}$, (decrease of formic acid concentration in the final mixture of eluent by increasing $\delta_{\mathrm{ACN}}$ and decrease of hydrogen ion as the counter ion), the IE interactions should become weaker by the increase of $\delta_{\mathrm{ACN}}$ in these experiments, i.e., the retention behavior will be contrary to RP interaction. The investigation of the separation performance was based on parameters shown in ESM Table S1.

\section{Method validation}

To investigate the linearity of the method, three series of 10 samples with concentrations 1, 2, 5, 10, 20, 50, 100, 200, 500, $1000 \mu \mathrm{g} / \mathrm{L}$ were chosen based on DIN 38402-51 [45] and analyzed. Mandel's test was calculated based on [46]. In brief, an $F$ test was performed to compare linear and second-order polynomial calibration according to the following equation:

$F=\frac{(n-2) \times S_{y / x, l i n}{ }^{2}-(n-3) \times S_{y / x, \text { non }}{ }^{2}}{S_{y / x, \text { non }}{ }^{2}}$

where $n$ is the number of calibration points; $\mathrm{S}_{\mathrm{y} / \mathrm{x} \text {, lin }}$ and $\mathrm{S}_{\mathrm{y} / \mathrm{x} \text {,non }}$ are the standard error of the linear and nonlinear regression, respectively.

The method detection limit was quantified according to EPA [47] by analyzing nine different samples containing a mixture of all compounds, each with a concentration of 
$25 \mu \mathrm{g} / \mathrm{L}$. Measurements were performed in 3 different batches in 3 different days and method detection limit (MDL) was calculated according to Eq. 5:

$\mathrm{MDL}=t_{(n-1, \quad 1-\alpha=0.99)} \times S_{S}$

where $t_{(n-1,0.99)}$ is Student's $t$ value for a single-tailed 99th percentile (2.896 for $n=9$ ), and $S_{\mathrm{s}}$ is the standard deviation of measured samples.

The performance of the method was investigated in river water. The river water was filtered by $0.45-\mu \mathrm{m}$ cellulose acetate membranes and stored in the refrigerator at $\approx 5{ }^{\circ} \mathrm{C}$ until further use. Loss of the polar NCHs, e.g., due to sorption in this step, is negligible [33]. The sample had a TOC concentration of $3.53 \mathrm{mg} / \mathrm{L}$ and a $\mathrm{pH}$ of 7.87 . Portions of $10 \mathrm{~mL}$ surface water samples were spiked with different volumes of the stock solution of the NCHs (mixture, dissolved in water, concentration: $10 \mathrm{mg} / \mathrm{L}$ ) to prepare six different concentration levels. These samples were measured in three nonconsecutive days, each in triplicate using freshly made eluent by the same operator. Recoveries were calculated as the average of all recoveries within the whole method validation studies. By utilizing analysis of variance (ANOVA), the variation of different performance parameters within a day (repeatability) and between days (intermediate precision) were calculated according to the Eurachem Guide [48].

The matrix effect was assessed by comparing the slope of spiked river water samples with ultrapure water samples according to Eq. 6.

Matrix effect $=\left(\frac{\text { Slope in spike samples }}{\text { Slope in ultrapure water }}-1\right) \times 100$

\section{Results and discussion}

\section{Method development}

Void time was determined by injecting $\mathrm{NaBr}$ and measurement of bromide at different $\mathrm{ACN}$ volume fractions $\left(\delta_{\mathrm{ACN}}\right)$ in negative ionization mode. The experiment was performed at the same chromatographic conditions used for determination of chromatographic behavior (section 2.2). As expected, no trend in void time was observed regarding $\delta_{\mathrm{ACN}}$, ranging between 1.19 and $1.20 \mathrm{~min}$.

Using the void time and retention times, retention factors were calculated at different $\delta_{\mathrm{ACN}}$ (Fig. 1). It was observed that an increase of $\delta_{\mathrm{ACN}}$ leads to a decrease in retention time and $\log \left(\mathrm{k}^{\prime}\right)$ for pyridazine and pyrazole. Therefore, these two compounds mainly interact via RP mode. It is also worth mentioning that at lower $\delta_{\mathrm{ACN}}$ pyrazole elutes later than pyridazine, while at higher fractions, the order of elution changes. On the other hand, the stronger bases imidazole, pyridine, and

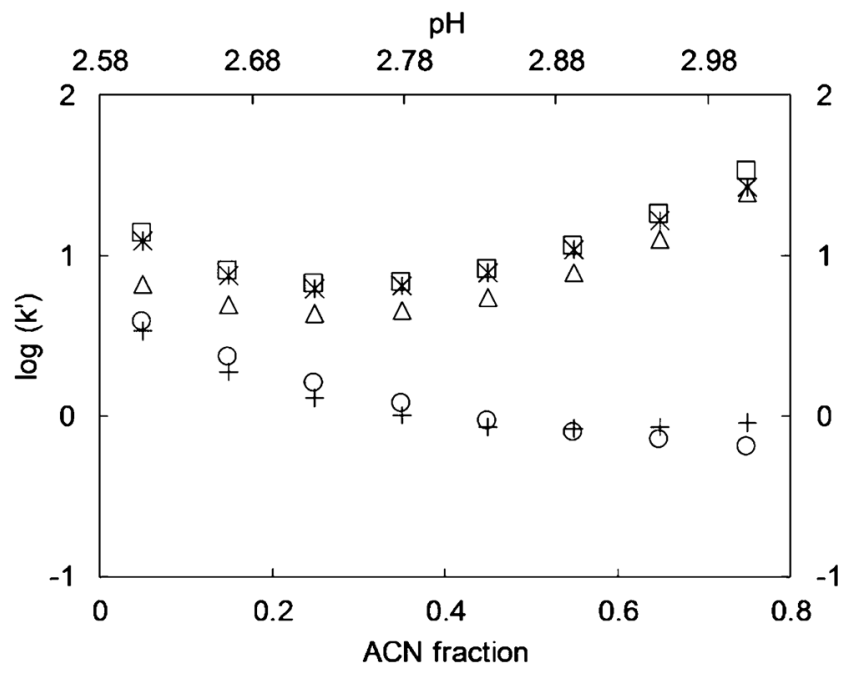

Fig. 1 Logarithm of retention factor $\left(\log \left(\mathrm{k}^{\prime}\right)\right)$ in isocratic elution of $\mathrm{NCHs}$ at different $\mathrm{ACN}$ volume fractions and the $\mathrm{pH}$ of the final eluent mixture. Imidazole (triangles), pyrazole (circles), pyridine (stars), pyridazine (crosses), and piperidine (squares). Eluent A: water $+0.1 \%$ FA, Eluent B: ACN. Flowrate $300 \mu \mathrm{L} / \mathrm{min}, 5 \mu \mathrm{L}$ injection volume. Separation column: Primesep 200

piperidine (c.f. $\mathrm{pKa}$ values, Table 1) display a first decrease of the retention factor until $\delta_{\mathrm{ACN}}$ reaches 0.25 . At $\delta_{\mathrm{ACN}}>0.25$ retention factor increases. This indicates that at $\delta_{\mathrm{ACN}} \leq 0.25$, these three compounds interact via RP interactions and at higher $\delta_{\mathrm{ACN}} \geq 0.25$ via ion exchange interactions. This can be explained as follows. Pyridazine and pyrazole are mainly present as neutral species during the whole range of $\delta_{\mathrm{ACN}}$, and thus, hydrophobic interactions may be most important. In the case of imidazole, pyridine, and piperidine, cationic species prevail in the whole range of applied $\delta_{\mathrm{ACN}}$ and can thus be separated by ion exchange interactions. The minimum of $\log \left(\mathrm{k}^{\prime}\right) \delta_{\mathrm{ACN}}$ at 0.25 indicates that imidazole, pyridine, and piperidine also interact by the RP mode of the MM-column, which are, however, suppressed with increasing ACN fractions and cannot be observed at $\delta_{\mathrm{ACN}}>0.25$. The exemplary chromatogram in ESM Fig. S1 illustrates how the retention time of imidazole and pyrazole increases and decreases by the increase of $\delta_{\mathrm{ACN}}$, respectively.

Efficiency and asymmetry are almost constant for imidazole, pyridine, and piperidine for all $\delta_{\mathrm{ACN}}$, except for 0.05 in which pyridine and piperidine show somewhat lower efficiency (ESM Figs. S2 and S3). On the other hand, for pyridazine and pyrazole, efficiency decreases with increasing $\delta_{\mathrm{ACN}}$. Higher peak widths are also observed for imidazole, pyridine, and piperidine congruent with higher retention time (ESM Fig. S4). Moreover, by comparing the selectivity (ESM Fig. S5) with the resolution (ESM Fig. S6) one can observe that they follow the same trend. It appears that the role of selectivity in the calculation of resolution (formula presented in ESM Table S1) is greater than the retention factor (Fig. 1) and efficiency (ESM Fig. S2). 


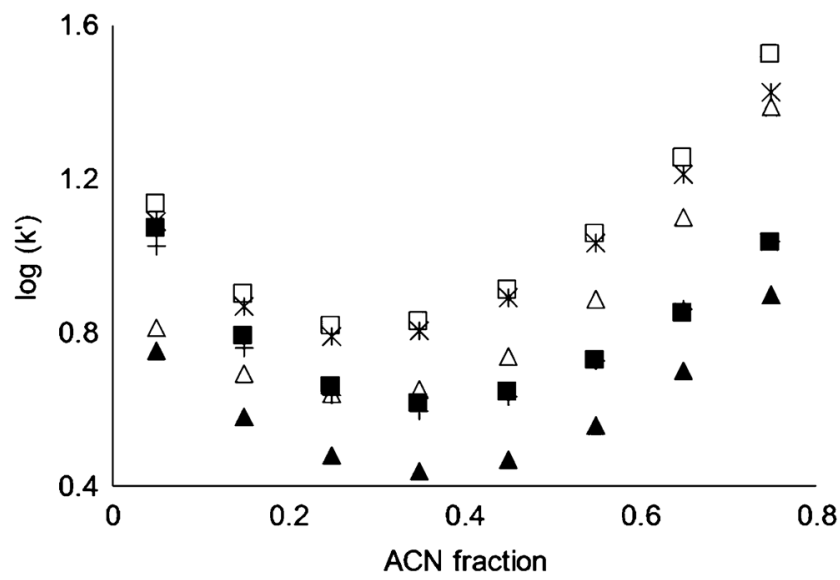

Fig. 2 Comparison between logarithm of retention factor $\left(\log \left(\mathrm{k}^{\prime}\right)\right)$ using two different eluent compositions. (1) Eluent A: water $+0.1 \%$ FA, Eluent $\mathrm{B}$ : ACN, imidazole (triangles) pyridine (stars), and piperidine (squares). (2) Eluent A: water $+0.1 \%$ FA, Eluent B: $\mathrm{ACN}+0.2 \%$ FA imidazole (filled triangles), pyridine (crosses), and piperidine (filled squares). Flowrate $300 \mu \mathrm{L} / \mathrm{min}, 5 \mu \mathrm{L}$ injection volume. Separation column: Primesep 200

Figure 1 also represents the relation between $\log (\mathrm{k})$ and $\mathrm{pH}$. According to Eq. 3 [44] the increase in the $\mathrm{pH}$ of final the eluent mixture is linear up to $\delta_{\mathrm{ACN}}=0.6$. Therefore, the retention of the analytes with IE interaction should also increase, as $\mathrm{H}^{+}$competes with the cationic analytes for ion exchange moieties (Eq. 2). Moreover, pyrazole and pyridazine are mostly present as neutral species in the $\mathrm{pH}$ between 2.6 to 2.9 and thus interact with RP. On the other hand, imidazole, pyridine, and piperidine are present as cations in the $\mathrm{pH}$ range of the eluent mixture and thus, the role of IE interaction is relevant for them. The U-shaped correlation of $\mathrm{pH}$ vs. $\log (\mathrm{k})$ for piperidine, pyridine, and imidazole indicates that two interaction modes work at the same time (i.e., RP and IE interactions) while in the range of linear increase at higher $\delta_{\mathrm{ACN}}$, IE interactions prevail. This type of U-shaped retention behavior is known to happen in HILIC phases [49] and was also previously observed in MMLC using other mixed-mode stationary phases $[14,50]$. Montes et al. [38] described this as showing RP retention at low $\delta_{\mathrm{ACN}}$ and HILIC-like retention at high $\delta_{\mathrm{ACN}}$ for MMLC.
In another set of experiments, both components of the eluent, i.e., water and $\mathrm{ACN}$, were acidified with $0.1 \%$ and $0.2 \%$ FA, respectively in order to investigate the suppression of IE at higher $\delta_{\mathrm{ACN}}$. Compared to the eluent with non-acidified $\mathrm{ACN}$, the increase of retention factor at $\delta_{\mathrm{ACN}}>0.45$ is less pronounced (Fig. 2). This can be explained by a constant elution strength for the IE mechanisms which corroborates that IE is indeed an important separation mechanism in the case of imidazole, pyridine, and piperidine. Substantial decrease of retention time by the increase of FA concentration for amines with $\mathrm{p} K_{\mathrm{a}}$ values of the corresponding acids above 8 was also previously observed by other researchers [39]. On the other hand, the hydrophilic interactions that are relevant in HILIC seem to be not completely suppressed, leading to the observed increase of the retention at $\delta_{\mathrm{ACN}}>0.45$. Contrary to RP and IE interactions (Eqs. 1 and 2), the relation between $\log \left(\mathrm{k}^{\prime}\right)$ and $\delta_{\mathrm{ACN}}$ in HILIC interactions is not first order. HILIC is modeled as having RP interaction in low $\delta_{\mathrm{ACN}}$ and normal phase (NP) interaction at high $\delta_{\mathrm{ACN}}$ according to [49].

$\log \mathrm{k}^{\prime}=m_{1} \times\left(1-\delta_{\mathrm{ACN}}\right)-m_{2} \times \log \left(1-\delta_{\mathrm{ACN}}\right)+$ constant $(7)$

where $m_{1}$ and $m_{2}$ are the empirical constants related to RP and NP interactions, respectively. Equation 4 can well describe the chromatographic behavior of all the compounds under investigation. Calculated parameters are presented in Table S2 and Fig. S7 (see ESM) represents the modeled data. All in all, it can be confirmed that $\mathrm{NCHs}$ that have basic properties follow a separation based on three interactions (RP/IE/HILIC). These multiple interactions provide many options to improve a separation from compounds which have fewer interactions with the stationary phase.

Based on the above data, a method was developed for the detection of these $\mathrm{NCH}$ in a surface water matrix to achieve proper retention and adequate separation from other constituents of the sample to avoid interferences during ESI [51]. The chromatographic method optimization was performed to achieve the best peak shape in a short runtime ( $\mathrm{k}^{\prime}, 2$ to 5$)$. As can be seen from Fig. $2, \mathrm{k}^{\prime}$ of $5\left(\log \left(\mathrm{k}^{\prime}\right) \approx 0.7\right)$ can be achieved for stronger bases only with the second set of eluents and at the middle $\delta_{\mathrm{ACN}}$. Using different compositions of the

Table 2 Method performance parameters for measurement of NCHs. Flowrate $300 \mu \mathrm{L} / \mathrm{min}, 5 \mu \mathrm{L}$ injection volume. Separation column: Primesep 200 , Gradient according to ESM Table S3. MS conditions according to ESM Table S4

\begin{tabular}{llllllll}
\hline Compound & $\begin{array}{l}\text { Retention }\left(t_{\mathrm{R}}\right) \\
{[\mathrm{min}]}\end{array}$ & $\begin{array}{l}\text { Peak width }\left(W_{50}\right) \\
{[\mathrm{min}]}\end{array}$ & $\begin{array}{l}\text { Peak asymmetry } \\
\left(A_{\mathrm{s}}\right)\end{array}$ & $\begin{array}{l}\text { Retention factor } \\
\left(\mathrm{k}^{\prime}\right)\end{array}$ & $\begin{array}{l}\text { Selectivity } \\
(\alpha)\end{array}$ & $\begin{array}{l}\text { Efficiency }(\mathrm{N}) \\
{[\mathrm{plates} / \mathrm{column}]}\end{array}$ & $\begin{array}{l}\text { Resolution } \\
\left(R_{\mathrm{s}}\right)\end{array}$ \\
\hline Imidazole & 8.93 & 0.29 & 1.03 & 3.65 & 1.74 & 4399 & 5.55 \\
Pyrazole & 5.94 & 0.26 & 1.65 & 2.09 & 1.18 & 2960 & 1.43 \\
Pyridine & 12.48 & 0.22 & 1.27 & 5.50 & - & 2410 & 1.51 \\
Pyridazine & 5.31 & 0.24 & 1.32 & 1.77 & 1.04 & 17062 & - \\
Piperidine & 12.92 & 0.23 & 1.16 & 5.73 & 1.12 \\
\hline
\end{tabular}


Table 3 Method performance parameters for measurement of NCHs. Flowrate $300 \mu \mathrm{L} / \mathrm{min}, 5 \mu \mathrm{L}$ injection volume. Separation column: Primesep 200 , Gradient according to ESM Table S3. MS condition according to ESM Table S4

\begin{tabular}{|c|c|c|c|c|c|c|}
\hline Compound & $\begin{array}{l}\text { Slope (sensitivity) } \\
(\text { peak area } \times \mathrm{L} / \mu \mathrm{g})\end{array}$ & $\begin{array}{l}\text { Intercept } \\
\text { (peak area) }\end{array}$ & $R^{2}$ & $\begin{array}{l}\text { Method standard deviation } \\
(\mu \mathrm{g} / \mathrm{L})\end{array}$ & $\begin{array}{l}\text { Linear range } \\
(\mu \mathrm{g} / \mathrm{L})\end{array}$ & $\begin{array}{l}\mathrm{MDL} \\
(\mu \mathrm{g} / \mathrm{L})\end{array}$ \\
\hline Imidazole & $(69.8 \pm 0.2) \times 10^{3}$ & $(-1 \pm 0.4) \times 10^{5}$ & 0.9999 & 1.55 & $1-500$ & 6.11 \\
\hline Pyrazole & $(81.7 \pm 0.4) \times 10^{3}$ & $(-2.2 \pm 0.8) \times 10^{5}$ & 0.9998 & 2.44 & $1-500$ & 3.62 \\
\hline Pyridine & $(186.8 \pm 0.8) \times 10^{3}$ & $(-0.6 \pm 0.1) \times 10^{5}$ & 0.9999 & 1.88 & $1-500$ & 3.3 \\
\hline Pyridazine & $(59.4 \pm 0.8) \times 10^{3}$ & $(-4.7 \pm 1.6) \times 10^{5}$ & 0.9991 & 6 & $5-500$ & 4.93 \\
\hline Piperidine & $(174.1 \pm 0.7) \times 10^{3}$ & $(-4.7 \pm 1.3) \times 10^{5}$ & 0.9999 & 1.93 & $1-500$ & 2.74 \\
\hline
\end{tabular}

mobile phase and gradient elution, the final method was developed according to ESM Table S3. MS measurements were done in two modes: in single ion monitoring (SIM) to improve the sensitivity and in scan mode (ESM Table S4).

Using the abovementioned conditions, a separation with parameters shown in Table 2 was achieved. Under these conditions, the efficiency of pyridine and piperidine separation largely increased, while the other compounds did not change much compared to the previous measurements. The method performance is very good regarding peak width (13 to $18 \mathrm{~s}$ ) and asymmetry factors of maximum 1.65 , particularly taking into account that the best peak shapes were obtained for the compounds with no retention in RP (i.e., imidazole, pyridine, piperidine).

\section{Method validation}

Table 3 shows Mandel's test results for linearity and method detection limit (MDL). For all the compounds, calibrating by consideration of the highest investigated concentration $(1000 \mu \mathrm{g} / \mathrm{L})$ leads to a lack of linearity according to Mandel's test. Therefore, $500 \mu \mathrm{g} / \mathrm{L}$ is the highest linear point in the logarithmic range.

All the measured MDLs are between 3 and $6 \mu \mathrm{g} / \mathrm{L}$, according to Table 3 . It should be noted that no peaks were observed in blank samples; hence, no correction of MDL was required. For pyridine the detection limit of a previously developed method was reported to be $4.6 \mu \mathrm{g} / \mathrm{L}$ achieved by extraction of $1 \mathrm{~L}$ water into $1 \mathrm{~mL}$ methylene chloride followed by GC-MS [52]. Using electrical fieldstimulated liquid-phase microextraction followed by HPLC-UV [53], $0.01 \mu \mathrm{g} / \mathrm{L}$ MDL was also achieved for pyridine. Pyrazole has been measured using vacuumassisted headspace solid-phase microextraction followed by $\mathrm{GC}-\mathrm{MS}(\mathrm{LOQ}=0.04 \mu \mathrm{g} / \mathrm{L})[54]$, or by injecting sample in volumes as high as $90 \mu \mathrm{L}$ in LC followed by MS in multiple reaction monitoring $(0.05 \mu \mathrm{g} / \mathrm{L})$ [55]. Utilizing conductivity detector and RP columns provided detection limits for ionic liquids of piperidinium, pyridinium, and imidazolium in the milligram per liter range [56, 57]. It can be stated that the MMLC method is similarly sensitive, considering that it could be improved by a factor of 1000 using an appropriate extraction method. The method standard deviation (residual standard deviation divided by slope) is similar for most of the investigated compounds. Pyridazine, however, showed an approximately three times higher method standard deviation than the average.

Table 4 shows method performance in river samples. The recoveries for imidazole, pyridine, and piperidine are more than $90 \%$, while pyridazine showed a recovery of ca. $30 \%$. In a similar manner, a relatively small matrix effect is observed in the measurement of NCHs except for pyridazine (ESM Fig. S8). One reason for the small matrix effect can be the low flow rate in this method, which can reduce matrix effects in ESI [51]. This can be further improved by post-column splitting [58] or using smaller

Table 4 Recovery, repeatability, and intermediate precision for measurement NCHs in spiked surface water. Flowrate $300 \mu \mathrm{L} / \mathrm{min}, 5 \mu \mathrm{L}$ injection volume. Separation column: Primesep 200, Gradient according to ESM Table S3. MS condition according to ESM Table S4

\begin{tabular}{|c|c|c|c|}
\hline Compound & Average recovery $(\%)$ & Repeatability (\%RSD) & Intermediate precision (\%RSD) \\
\hline Imidazole & 92 & 1.1 & 5.17 \\
\hline Pyrazole & 77 & 3.12 & 6.82 \\
\hline Pyridine & 96 & 0.92 & 4.09 \\
\hline Pyridazine & 32 & 7.21 & 26.66 \\
\hline Piperidine & 91 & 0.74 & 4.69 \\
\hline
\end{tabular}


Table 5 Repeatability and intermediate precision of retention time, peak width, and peak asymmetry measured for NCHs in spiked surface water Flowrate $300 \mu \mathrm{L} / \mathrm{min}, 5 \mu \mathrm{L}$ injection volume. Separation column:
Primesep 200, Gradient according to ESM Table S3. MS condition according to ESM Table S4

\begin{tabular}{|c|c|c|c|c|c|c|}
\hline \multirow[t]{2}{*}{ Compound } & \multicolumn{2}{|l|}{ Retention time } & \multicolumn{2}{|l|}{ Peak width } & \multicolumn{2}{|c|}{ Peak asymmetry } \\
\hline & $\begin{array}{l}\text { Repeatability } \\
\text { (\%RSD) }\end{array}$ & $\begin{array}{l}\text { Intermediate precision } \\
\text { (\%RSD) }\end{array}$ & $\begin{array}{l}\text { Repeatability } \\
\text { (\%RSD) }\end{array}$ & $\begin{array}{l}\text { Intermediate precision } \\
\text { (\%RSD) }\end{array}$ & $\begin{array}{l}\text { Repeatability } \\
\text { (\%RSD) }\end{array}$ & $\begin{array}{l}\text { Intermediate precision } \\
(\% \mathrm{RSD})\end{array}$ \\
\hline Imidazole & 0.15 & 0.4 & 3.89 & 3.85 & 0.04 & 0.05 \\
\hline Pyrazole & 0.15 & 0.28 & 4.45 & 5.07 & 0.04 & 0.04 \\
\hline Pyridine & 0.08 & 0.18 & 2.40 & 2.44 & 0.02 & 0.02 \\
\hline Pyridazine & 23.6 & 24.9 & 23.37 & 30.74 & 0.37 & 0.51 \\
\hline Piperidine & 0.09 & 0.2 & 2.14 & 2.15 & 0.03 & 0.03 \\
\hline
\end{tabular}

dimensions of the column with proportionally lower flow rate. Moreover, using other ionization sources such as APCI [59] and APPI [60] might also help to reduce the matrix effect as they are less prone to interferences. The high matrix effect for pyridazine affected the overall recovery of the compound. It can be stated that the method is not performing well for the detection of pyridazine in the tested river water matrix.

Moreover, higher intermediate precision in Table 4 can be attributed to a higher deviation from actual values in different days due to further variations of solvents, (room) temperatures, performance of the instrument (e.g., condition of seals, capillaries), etc. in comparison to triplicate injection within a day. While the intermediate precision for NCHs except pyridazine was ca. $5.2 \%$, repeatability had a clear better performance for compounds with small or no tailing, i.e., imidazole, pyridine, and piperidine.

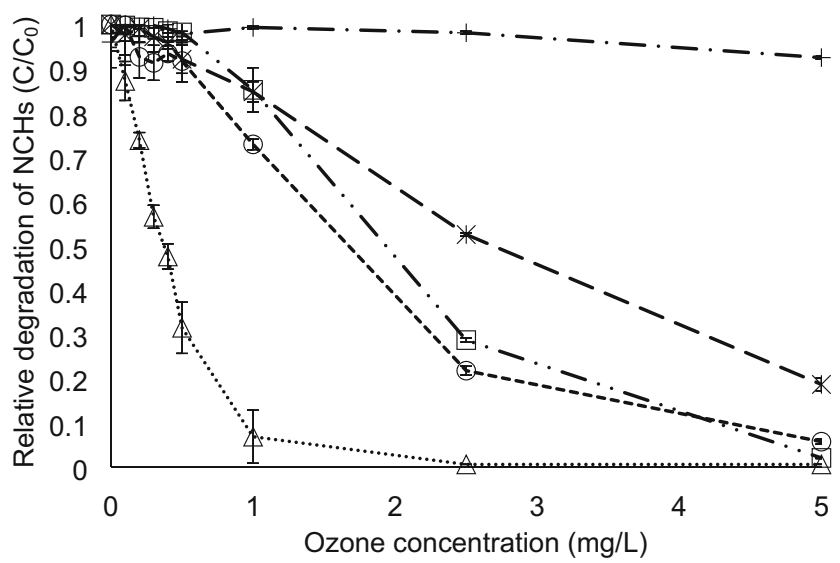

Fig. 3 Relative degradation of $\mathrm{NCHs}$ with ozone in a surface water matrix spiked with a mixture of compounds with a concentration of $100 \mu \mathrm{g} / \mathrm{L}$ of each measured by LC-MS method. Imidazole (triangles, dotted line), pyrazole (circles, dashed line), pyridine (stars, long dashed line), pyridazine (crosses, long dash-dotted line), and piperidine (squares, long dash double dotted line). Error bars are the standard deviation of triplicate samples. Flowrate $300 \mu \mathrm{L} / \mathrm{min}, 5 \mu \mathrm{L}$ injection volume. Separation column: Primesep 200, Gradient according to ESM Table S3. MS condition according to ESM Table S4. Note that recovery of pyridazine was $30 \%$
Pyridazine also showed worse performance in terms of retention time, peak width, and peak asymmetry with over $20 \%$ RSD (Table 5). Moreover, a difference between repeatability and intermediate precision of retention times was observed for all compounds due to the decrease in retention time. However, both within-a-day and between-days variation are very small in absolute terms, except for pyridazine. The highest intermediate precision $(0.4 \%$ for imidazole) originates from the highest decrease of $4 \mathrm{~s}$ in retention time in three nonconsecutive days. The peak width and asymmetry had no significant difference in intraday and interday measurements for NCHs other than pyridazine.

\section{Application in ozonation of $\mathrm{NCH}$-containing matrix}

As mentioned before, NCHs have to be abated during wastewater treatment and in drinking water since NCHs may contaminate drinking water resources and ozonation is one of the methods $[11,18]$. A set of experiments was designed to follow the reduction of $\mathrm{NCH}$ using ozone, in which river water was spiked to $100 \mu \mathrm{g} / \mathrm{L} \mathrm{NCHs} \mathrm{each.} \mathrm{Afterwards,} \mathrm{the} \mathrm{solution} \mathrm{was}$ divided into $10 \mathrm{~mL}$ samples in which ozone was dosed. The samples were analyzed with the developed LC-MS method at minimum $24 \mathrm{~h}$ after ozone was dosed for assuring full ozone depletion (note that typical lifetimes of ozone in ozonation are below $1 \mathrm{~h}$ ). Figure 3 shows that ozonation has different efficiencies in the reduction of NCHs. Imidazole is the most efficiently eliminated compound, followed by pyrazole. Both compounds may be degraded at typical conditions of drinking water ozonation. The other compounds seem to be much more ozone refractory. Pyrazole, piperidine, and pyridine require elevated ozone dosages, which could result in undesired byproduct formation. Pyridazine was not degraded in the present experiment, which covers a wide range of ozone dosages applied in drinking water. The results show that the developed method can be readily applied to analyze NCHs in real water samples and monitor their degradation in oxidation processes. 


\section{Conclusion}

The present work has shown that the MMLC is a complementary alternative for HILIC in the separation of polar compounds such as NCHs. Decent knowledge on the separation mechanisms largely helps to develop and optimize methods for their separation. The successful measurement of the selected NCHs should also facilitate the use of MMLC for the quantification of other $\mathrm{NCHs}$ and polar compounds that are difficult to retain in RPLC, such as 1,2,4-Triazole. Moreover, short run time, no sample preparation, and internal standard make this method, time-efficient, robust, and cheap. However, to further increase sensitivity for environmental monitoring, higher injection volumes or enrichment methods that were recently reported such as multi-layer solid-phase extraction [32], vacuum-assisted evaporative [61], or freeze-drying [62] might be necessary. It was demonstrated that the present method could be used to determine $\mathrm{NCHs}$ in trace concentrations in real water samples and to monitor their abatement during water treatment processes such as oxidation processes.

Acknowledgments The present work was supported by the German Academic Exchange Service (DAAD) with funding from the German Federal Ministry of Education and Research (BMBF).

Funding Information Open Access funding provided by Projekt DEAL.

Compliance with ethical standards No data, text, or theories by others are presented without citation. Furthermore, the authors declare that no research was done on humans and/or animals in the present study.

Conflict of interest The authors declare that there are no conflicts of interest.

Open Access This article is licensed under a Creative Commons Attribution 4.0 International License, which permits use, sharing, adaptation, distribution and reproduction in any medium or format, as long as you give appropriate credit to the original author(s) and the source, provide a link to the Creative Commons licence, and indicate if changes were made. The images or other third party material in this article are included in the article's Creative Commons licence, unless indicated otherwise in a credit line to the material. If material is not included in the article's Creative Commons licence and your intended use is not permitted by statutory regulation or exceeds the permitted use, you will need to obtain permission directly from the copyright holder. To view a copy of this licence, visit http://creativecommons.org/licenses/by/4.0/.

\section{References}

1. Grosser RJ, Vestal JR, Warshawsky D. Mineralization of polycyclic and N-heterocyclic aromatic compounds in hydrocarboncontaminated soils. Environ Toxicol Chem. 1995;14(3):375-82.

2. Ansari A, Ali A, Asif M. Shamsuzzaman. Review: biologically active pyrazole derivatives. New J Chem. 2016;41(1):16-41.

3. Berger U, Ost N, Sättler D, Schliebner I, Kühne R, Schüürman G, et al. Assessment of persistence, mobility and toxicity (PMT) of
167 REACH registered substances. Umweltbundesamt (UBA). 9/2018.

4. Sims GK, O’Loughlin EJ, Crawford RL. Degradation of pyridines in the environment. Crit Rev Environ Control. 1989;19(4):309-40.

5. Pagga U, Bachner J, Strotmann U. Inhibition of nitrification in laboratory tests and model wastewater treatment plants. Chemosphere. 2006;65(1):1-8.

6. Bi E, Schmidt TC, Haderlein SB. Sorption of heterocyclic organic compounds to reference soils: column studies for process identification. Environ Sci Technol. 2006;40(19):5962-70.

7. Broholm MM, Broholm K, Arvin E. Sorption of heterocyclic compounds on natural clayey till. J Contam Hydrol. 1999;39(3-4):183200.

8. Lee ST, Rhee SK, Lee GM. Biodegradation of pyridine by freely suspended and immobilized Pimelobacter sp. Appl Microbiol Biotechnol. 1994;41(6):652-7.

9. Roper WL. Toxicological profile for pyridine. Agency for Toxic Substances and Disease Registry, US Public Health Service. 1992.

10. Zamfirescu D, Grathwohl P. Occurrence and attenuation of specific organic compounds in the groundwater plume at a former gasworks site. J Contam Hydrol. 2001;53(3-4):407-27.

11. Fleig M, Scheurer M, Schmidt CK. Wesentliche Ergebnisse aus dem ARW-Untersuchungs - programm 2018. In: Jahresbericht. Köln: Arbeitsgemeinschaft Niederrhein-Wasserwerke; 2018. p. $15-54$.

12. Stroomberg GJ. RIWA position INEOS permit application ozone installation. 2017. Available from: https://www.riwa-rijn.org/wpcontent/uploads/2018/02/RIWA-position-INEOS-permitapplication-ozone-installation.pdf. Accessed on 6 Nov 2019.

13. Stuber HA, Leenheer JA. Selective concentration of aromatic bases from water with a resin adsorbent. Anal Chem. 1983;55(1):111-5.

14. Lamouroux C, Foglia G, Le Rouzo G. How to separate ionic liquids: use of hydrophilic interaction liquid chromatography and mixed mode phases. J Chromatogr A. 2011;1218(20):3022-8.

15. Padoley KV, Mudliar SN, Pandey RA. Heterocyclic nitrogenous pollutants in the environment and their treatment options - an overview. Bioresour Technol. 2008;99(10):4029-43.

16. Soltanzadeh Z, Imanzadeh G, Noroozi-Pesyan N, Șahin E. Green synthesis of pyrazole systems under solvent-free conditions. Green Chem Lett Rev. 2017;10(3):148-53.

17. Vitaku E, Smith DT, Njardarson JT. Analysis of the Structural Diversity, Substitution Patterns, and Frequency of Nitrogen Heterocycles among U.S. FDA Approved Pharmaceuticals. J Med Chem. 2014;57(24):10257-74.

18. Lowenbach W, Schlesinger J, King J. Toxic pollutant Identificatio: acrylonitrile manufacturing. McLean, Virginia: EPA IMPQE Series; 1978.

19. Wang Z, Xu X, Yang F, Tan Z, Chen J. Biodegradability of some nitrogenous heterocyclic compounds and co-degradationwith phenol by denitrifiers in anoxic sludge reactor. Water Sci Technol. 2015;72(3):347-53.

20. Padoley KV, Rajvaidya AS, Subbarao TV, Pandey RA. Biodegradation of pyridine in a completely mixed activated sludge process. Bioresour Technol. 2006;97(10):1225-36.

21. Lide DR. CRC Handbook of chemistry and physics. 90th ed. Boca Raton: CRC Press; 2010.

22. Umweltbundesamt. Bundesanzeiger. 2017 Aug;August:1-156. Available from: https://www.bundesanzeiger.de/ebanzwww/ w e x s s e rvlet? s e s s i o n. s e s s i o n i d = 6a5a4d191d0f9dba22ec6b7ee3ec70cf\&page.navid=official_view publicationtoofficial_start\&fts_search list.destHistoryId $=\overline{3} 0586$. Accessed 29 Sep 2019.

23. Neumann M, Schliebner I. Protecting the sources of our drinking water. second, revised edition. German Environment Agency; 2017. Available from: https://www.umweltbundesamt.de/en/ 
publikationen/protecting-the-sources-of-our-drinking-waterfrom Accessed 21 Oct 2019.

24. Umweltbundesamt. Liste der nach GOW bewerteten Stoffe. 2019. p. 1-2. Available from: https://www.umweltbundesamt.de/ dokument/liste-nach-gow-bewerteten-stoffe. Accessed Oct 22 2019.

25. European Chemicals Agency. Information from Registration Dossiers. 2019. Available from: https://echa.europa.eu//-/ registered-dossier/23403/5/3/1. Accessed 22 Oct 2019.

26. Tekle-Röttering A, Jewell KS, Reisz E, Lutze HV, Ternes TA, Schmidt W, et al. Ozonation of piperidine, piperazine and morpholine: kinetics, stoichiometry, product formation and mechanistic considerations. Water Res. 2016;88:960-71.

27. Tekle-Röttering A, Reisz E, Jewell KS, Lutze HV, Ternes TA, Schmidt W, et al. Ozonation of pyridine and other N-heterocyclic aromatic compounds: kinetics, stoichiometry, identification of products and elucidation of pathways. Water Res. 2016;102:58293.

28. McCalley DV. The challenges of the analysis of basic compounds by high performance liquid chromatography: some possible approaches for improved separations. J Chromatogr A. 2010;1217(6):858-80.

29. Lobrutto R. Retention of ionizable compounds in HPLC. Seton Hall University Dissertations and Theses (ETDs); 2000.

30. Zhu Y, Ren H, Wei Y, Bie Z, Ji L. Determination of imidazole, 4methylimidazole, and 2-methylimidazole in cigarette additives by ultra-high performance liquid chromatography. Anal Lett. 2015;48(17):2708-14.

31. Reemtsma T, Berger U, Arp HPH, Gallard H, Knepper TP, Neumann M, et al. Mind the gap: persistent and mobile organic compounds-water contaminants that slip through. Environ Sci Technol. 2016;50(19):10308-15.

32. Köke N, Zahn D, Knepper TP, Frömel T. Multi-layer solid-phase extraction and evaporation - enrichment methods for polar organic chemicals from aqueous matrices. Anal Bioanal Chem. 2018;410(9):2403-11.

33. Scheurer M, Brauch H-J, Schmidt CK, Sacher F. Occurrence and fate of nitrification and urease inhibitors in the aquatic environment. Environ Sci Process Impacts. 2016;18(8):999-1010.

34. Schmidt TC. Recent trends in water analysis triggering future monitoring of organic micropollutants. Anal Bioanal Chem. 2018;410(17):3933-41.

35. Stepnowski P, Mrozik W. Analysis of selected ionic liquid cations by ion exchange chromatography and reversed-phase hihg performance liquid chromatography. J Sep Sci. 2005;28(2):149-54

36. Hawkins CA, Rud A, Guthrie ML, Dietz ML. Rapid quantification of imidazolium-based ionic liquids by hydrophilic interaction liquid chromatography: methodology and an investigation of the retention mechanisms. J Chromatogr A. 2015;1400:54-64.

37. Zhang K, Liu X. Reprint of "mixed-mode chromatography in pharmaceutical and biopharmaceutical applications.". J Pharm Biomed Anal. 2016;130:19-34.

38. Montes R, Aguirre J, Vidal X, Rodil R, Cela R, Quintana JB. Screening for polar chemicals in water by trifunctional mixedmode liquid chromatography-high resolution mass spectrometry. Environ Sci Technol. 2017;51(11):6250-9.

39. Li J, Shao S, Jaworsky MS, Kurtulik PT. Simultaneous determination of cations, zwitterions and neutral compounds using mixedmode reversed-phase and cation-exchange high-performance liquid chromatography. J Chromatogr A. 2008;1185(2):185-93.

40. Hoigné J, Bader H. Bestimmung von Ozon und Chlordioxid in Wasser mit der Indigo-Methode. Vom Wasser. 1980;55:261-80.

41. von Sonntag C, von Gunten U. Chemistry of ozone in water and wastewater treatment: IWA publishing; 2012.

42. Ordoñez EY, Quintana JB, Rodil R, Cela R. Computer assisted optimization of liquid chromatographic separations of small molecules using mixed-mode stationary phases. J Chromatogr A. 2012;1238:91-104.

43. Ståhlberg J. Retention models for ions in chromatography. J Chromatogr A. 1999;855(1):3-55.

44. Subirats X, Bosch E, Rosés M. Retention of ionisable compounds on high-performance liquid chromatography XVIII: $\mathrm{pH}$ variation in mobile phases containing formic acid, piperazine, tris, boric acid or carbonate as buffering systems and acetonitrile as organic modifier. J Chromatogr A. 2009;1216(12):2491-8.

45. DIN. 38402-51 Deutsche Einheitsverfahren zur Wasser-, Abwasser und Schlammuntersuchung - Allgemeine Angaben (Gruppe A) Teil 51: Kalibrierung von Analysenverfahren - Lineare Kalibrierfunktion (A 51). 2014.

46. Andrade JM, Gómez-Carracedo MP. Notes on the use of Mandel's test to check for nonlinearity in laboratory calibrations. Anal Methods. 2013;5(5):1145-9.

47. EPA US. Definition and procedure for the determination of the method detection limit, Revision 2. Environmental Protection Agency EPA. 2016.

48. Eurachem. Eurachem guide: the fitness for purpose of analytical methods - a laboratory guide to method validation and related topics. 2014;1-62.

49. Buszewski B, Noga S. Hydrophilic interaction liquid chromatography (HILIC)-a powerful separation technique. Anal Bioanal Chem. 2012;402(1):231-47.

50. Balkatzopoulou P, Fasoula S, Gika H, Nikitas P, Pappa-Louisi A. Retention prediction of highly polar ionizable solutes under gradient conditions on a mixed-mode reversed-phase and weak anionexchange stationary phase. J Chromatogr A. 2015;1396:72-6.

51. Kloepfer A, Quintana JB, Reemtsma T. Operational options to reduce matrix effects in liquid chromatography-electrospray ionisation-mass spectrometry analysis of aqueous environmental samples. J Chromatogr A. 2005;1067(1-2):153-60.

52. EPA US. Subchapter D - Water programs ( continued ) PART 136 - guidelines establishing test procedures for the analysis of pollutants. Water Pollut Control. 2003. Available from: https:// w w w . e c f r . g o v/ c g i - b i n/tex t - id x ? S I D = a6bb8a02b6d783f9356758b5ff0ed106\&mc $=$ true \&node $=p t 40.25$. 136\&rgn=div5\#se40.25.136 15. Accessed 22 Oct 2019.

53. Yamini Y, Seidi S, Pourali A, Rezazadeh M. Electrical fieldstimulated liquid-phase microextraction for trace analysis of pyridine and its derivatives in cigarette extract. J Iran Chem Soc. 2015;12(3):503-11.

54. Orazbayeva D, Kenessov B, Psillakis E, Nassyrova D, Bektassov M. Determination of transformation products of unsymmetrical dimethylhydrazine in water using vacuum-assisted headspace solidphase microextraction. J Chromatogr A. 2018;1555:30-6.

55. LANUV. ECHO-Stoffbericht Pyrazol. p. 1-13. Available from: https://www.lanuv.nrw.de/fileadmin/lanuv/analytik/pdf/ECHO_ Pyrazol 2017a.pdf. Accessed 29 Sept 2019.

56. Zhang XX, Liu YQ, Yu H, Zhang RQ. Rapid and simultaneous determination of piperidinium and pyrrolidinium ionic liquid cations by ion pair chromatography coupled with direct conductivity detection. Chin Chem Lett. 2017;28(1):126-30.

57. Huang X, Yu H, Dong YJ. Rapid and simultaneous determination of imidazolium and pyridinium ionic liquid cations by ion-pair chromatography using a monolithic column. Chin Chem Lett. 2012;23(7):843-6.

58. Kruve A, Leito I. Comparison of different methods aiming to account for/overcome matrix effects in LC/ESI/MS on the example of pesticide analyses. Anal Methods. 2013;5(12):3035-44.

59. Baken K, Kolkman A, van Diepenbeek P, Ketelaars H, van Wezel A. Signalering van "overige antropogene stoffen", en dan? De pyrazool- casus. 2016. Available from: https://www. h2owaternetwerk.nl/images/H2O-Online 1609-03 Pyrazool II Bakenetal.pdf. Accessed 07 Nov 2019. 
60. Trufelli H, Palma P, Famiglini G, Cappiello A. An overview of matrix effects in liquid chromatography-mass spectrometry. Mass Spectrom Rev. 2011;30(3):491-509.

61. Mechelke J, Longrée P, Singer H, Hollender J. Vacuum-assisted evaporative concentration combined with LC-HRMS/MS for ultratrace-level screening of organic micropollutants in environmental water samples. Anal Bioanal Chem. 2019;411(12):2555-67.
62. Montes R, Rodil R, Cela R, Quintana JB. Determination of persistent and mobile organic contaminants (PMOCs) in water by mixedmode liquid chromatography-tandem mass spectrometry. Anal Chem. 2019;91(8):5176-83.

Publisher's note Springer Nature remains neutral with regard to jurisdictional claims in published maps and institutional affiliations. 